\title{
New methods for evaluating physical and thermal comfort properties of orthotic materials used in insoles for patients with diabetes
}

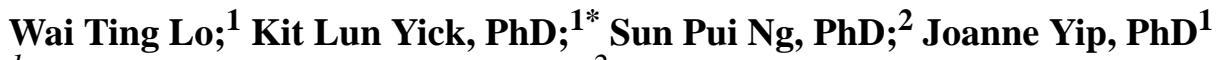 \\ ${ }^{1}$ Institute of Textiles and Clothing and ${ }^{2}$ Hong Kong Community College, The Hong Kong Polytechnic University, Hong \\ Kong
}

\begin{abstract}
Orthotic insoles are commonly used in the treatment of the diabetic foot to prevent ulcerations. Choosing suitable insole material is vital for effective foot orthotic treatment. We examined seven types of orthotic materials. In consideration of the key requirements and end uses of orthotic insoles for the diabetic foot, including accommodation, cushioning, and control, we developed test methods for examining important physical properties, such as force reduction and compression properties, insole-skin friction, and shear properties, as well as thermal comfort properties of fabrication materials. A novel performance index that combines various material test results together was also proposed to quantify the overall performance of the insole materials. The investigation confirms that the insole-sock interface has a lower coefficient of friction and shearing stress than those of the insole-skin interface. It is also revealed that material brand and the corresponding density and cell volume, as well as thickness, are closely associated with the performance of moisture absorption and thermal comfort. On the basis of the proposed performance index, practitioners can better understand the properties and performance of various insole materials, thus prescribing suitable orthotic insoles for patients with diabetic foot.
\end{abstract}

Key words: diabetic foot, friction, insole materials, performance index, physical properties, pressure redistribution, orthotic insoles, shearing, thermal comfort properties, ulceration.

\section{INTRODUCTION}

Foot ulcerations are a debilitating and costly complication for people with diabetes. Foot ulcers mainly develop as a result of sustained high pressure and mechanical stress on a particular area of the foot, frequently over bony prominences, such as the plantar surface of the toes and forefoot, which lead to necrosis and eventually the amputation of the foot or even the entire lower leg [1-3]. This might have a long-term influence, especially for the localized prominent areas, resulting in skeletal deformities [4]. Foot orthotic treatment is one of the primary means to handle diabetic foot problems. Custom-fabricated orthotic insoles that offer proper arch support can be worn to reduce the magnitude of patient exposure to pressure by redistributing the force of body weight acting through the feet over a large and accommodative surface so as to prevent neuropathic ulceration [5-11].

In most cases, the choice of foam materials is subjectively determined based on the experience of individual orthotists and practitioners. Despite anecdotal and clinical evidence of the beneficial effects of foot orthoses for the prevention of ulcerations on the neuropathic diabetic foot, there is a scarcity of scientific work that provides a comprehensive evaluation of orthotic materials and specifications for the development of foot orthoses [12]. The physical and

\footnotetext{
Abbreviations: EVA = ethyl vinyl acetate, ICC = intraclass correlation coefficient, $\mathrm{PE}=$ polyethylene, $\mathrm{PI}$ = performance index. *Address all correspondence to Kit Lun Yick, PhD; Institute of Textiles and Clothing, The Hong Kong Polytechnic University, Hung Hom, Hong Kong 852, China: +852-2766-6551; fax: +852-2773-1432. Email: Kit-lun.yick@polyu.edu.hk http://dx.doi.org/10.1682/JRRD.2013.01.0012
} 
mechanical properties - durability, resilience, compressive stiffness, and coefficient of friction-are generally taken as the key requirements for the evaluation and selection of suitable fabrication materials for orthotic insoles [13-14]. Particular attention is also paid to the pressure redistribution performance of the materials. Nevertheless, limited information is available on evaluating the shear loads between the plantar surface of the foot and liner of the insoles. This shear is defined as a type of mechanical stress that acts tangential to the plantar surface [15]. Its magnitude and direction are highly associated with the formation of calluses, and excessive shearing together with abnormal levels of repeated pressure that occurs within the foot or callus area has led to severe damage to soft tissue and results in ulcerations [16]. Experiments such as mounting a shear transducer onto a special flat inlay have been carried out to determine the shear location and compare the magnitude of shear forces between normal and diabetic subjects $[15,17]$. However, the special flat inlay associated with extra depth shoes must be acquired to accommodate the shear transducers that are solely used to examine the foot shear properties on particular subjects. Instead of measuring the shear loads between the foot skin and insole material, the stress between the foot and the shear transducer is recorded. An objective approach of evaluating material shear properties is suggested in this article so that the shear forces in terms of shear angles between the plantar surface of the foot and the insole materials can be measured and examined in a more standardized and generalized manner.

Traditional tests also neglect the importance of comfort perception in foot orthotic treatment, which affects the rate of compliance. A new in-shoe microclimate, which is relatively higher in temperature and humidity than the outer environment, is created during gait [13]. Factors such as previous experience, presence of pain or injury, and neurophysiology and psychological issues, as well as the design, contour, and hardness of insole fabrication may contribute to the overall comfort perception of foot orthoses [18-19]. By considering the prolonged use and hygiene of orthotic insoles, orthotic materials with good heat and moisture transportation properties not only provide wearers with more comfort without a damp feeling but also control bacteria from exponentially multiplying inside the in-shoe environment. However, because of lack of evidence in the literature, the understanding of the thermal comfort performance of different insole materials is somewhat limited.
In considering the wide range of orthotic materials and limited choices of suitable characterization technologies and that the efficacy of orthotic insoles still greatly depends on repeated trial and error based on the experience of individual orthotists and practitioners, the purpose of this research was to develop a systematic methodology to quantitatively assess the key properties of orthotic insole materials with regards to their practical use. The implementation of test methods for the characterization of key properties is based on the clinical practice of practitioners at local hospitals. Apart from traditional physical tests, this study will provide some preliminary data on evaluating the thermal comfort properties of insole materials. While repeated shear and friction loads between the plantar surface of the foot and insole may cause skin trauma, pain, and numerous complications, a new approach to measuring insole-skin friction behavior was demonstrated. On the basis of the results, a novel performance index (PI) for orthotic insole materials in response to their primary roles of accommodation, cushioning, and control was formulated. This will enable practitioners to select the most desirable insole materials to be used in insoles for patients with diabetes, thus optimizing compliance rate and efficacy of the orthotic treatment.

\section{METHODS}

\section{Test Materials}

Cellular polymer materials such as ethyl vinyl acetate (EVA) and polyethylene (PE) foam are commonly accepted as insole fabrication materials because of their availability in a wide range of hardnesses, thicknesses, densities, and structural and mechanical properties of diverse usefulness; the choice of materials can be closely associated with the intended use and efficacy of the custom-fabricated orthotic insoles. In this study, seven types of orthotic materials, including EVA and PE, that are frequently used for the production of diabetic foot insoles were sourced from the prosthetics and orthotics services of local hospitals. A summary of the foam specifications can be found in Table 1.

\section{Evaluation of Physical Properties}

Following the standard test method of measuring rubber resilience properties by vertical rebound (ASTM D2632; ASTM International; West Conshohocken, Pennsylvania), we adopted a new approach of measuring the 
Table 1.

Summary of orthotic material specifications.

\begin{tabular}{|c|c|c|c|c|c|c|c|}
\hline Brand & Sample & $\begin{array}{l}\text { Density } \\
\left(\mathrm{g} / \mathrm{cm}^{3}\right)\end{array}$ & $\begin{array}{l}\text { Hardness } \\
\text { (Shore A) }\end{array}$ & $\begin{array}{c}\text { Cell Size } \\
\left(10^{-3} \mu \mathrm{m}\right)\end{array}$ & Description & \multicolumn{2}{|c|}{$\begin{array}{l}\text { Thickness } \\
\text { (mm) }\end{array}$} \\
\hline Nora Lunairmed & A & 0.08 & 18 & 8.5-11 & Closed-cell EVA foam & & 6.2 \\
\hline Nora Lunairflex & $\mathrm{B}$ & 0.12 & 22 & $6.0-14.5$ & Closed-cell EVA foam (Perforated) & $\mathrm{B}(\mathrm{I})$ & 3.1 \\
\hline \multirow[t]{2}{*}{ Nora Lunalastike } & $\mathrm{C}$ & 0.23 & 25 & $11.0-14.5$ & Closed-cell EVA foam & $\mathrm{C}(\mathrm{I})$ & 2.9 \\
\hline & & & & & & $\mathrm{C}(\mathrm{II})$ & 5.9 \\
\hline & & & & & & $\mathrm{D}(\mathrm{II})$ & 8.1 \\
\hline & & & & & & $\mathrm{D}(\mathrm{III})$ & 10.3 \\
\hline Plastazote & $\mathrm{E}$ & 0.11 & 15 & $13.0-23.0$ & Closed-cell polyethylene foam & & 3.2 \\
\hline High Density EVA & $\mathrm{F}$ & 0.14 & 35 & $4.0-8.0$ & Closed-cell EVA foam & & 3.4 \\
\hline Pelite & G & 0.08 & 20 & 11.5-13.5 & Closed-cell polyethylene foam & & 2.9 \\
\hline
\end{tabular}

force reduction performance of orthotic insole materials in this study. A dynamic load cell was mounted on a base plate and laid underneath the tested materials (Figure 1). Each specimen was piled until a specific thickness of $18 \mathrm{~mm}$ was attained. A ball bearing was released onto the materials from inside an instrument at a height of $400 \mathrm{~mm}$. The load cell at the bottom of the instrument enabled accurate measurement of impact forces and triggered the data acquisition system. The maximum impact force was recorded. The force reduction capacity of the insole material was defined as a percentage of the peak forces with the insole specimen and ground surface (Equation (1)):

$$
\mathrm{FR}_{\mathrm{X}}(\%)=\left(1-\mathrm{F}_{\mathrm{X}} / \mathrm{F}_{\mathrm{o}}\right) \times 100 \%,
$$

where $\mathrm{FR}_{\mathrm{X}}$ is the force reduction percentage of the insole specimen, $F_{X}$ is the peak force measured for the insole specimen $(\mathrm{N})$, and $\mathrm{F}_{\mathrm{O}}$ is the peak force measured for the ground surface $(\mathrm{N})$.

The compression stress of the insole materials was then measured with an Instron tensile tester (Instron, Model 4411; Norwood, Massachusetts). A standard test method, International Organization for Standardization 3386-1:1998, was adopted to determine the stress/strain characteristics in compression. The force needed to compress a tested material to a specified deformation, 40 percent with regard to the initial thickness, was measured. The orthotic materials with high compressive stress were able to withstand deformation loads and retain their original shape and design. Nevertheless, it could be difficult

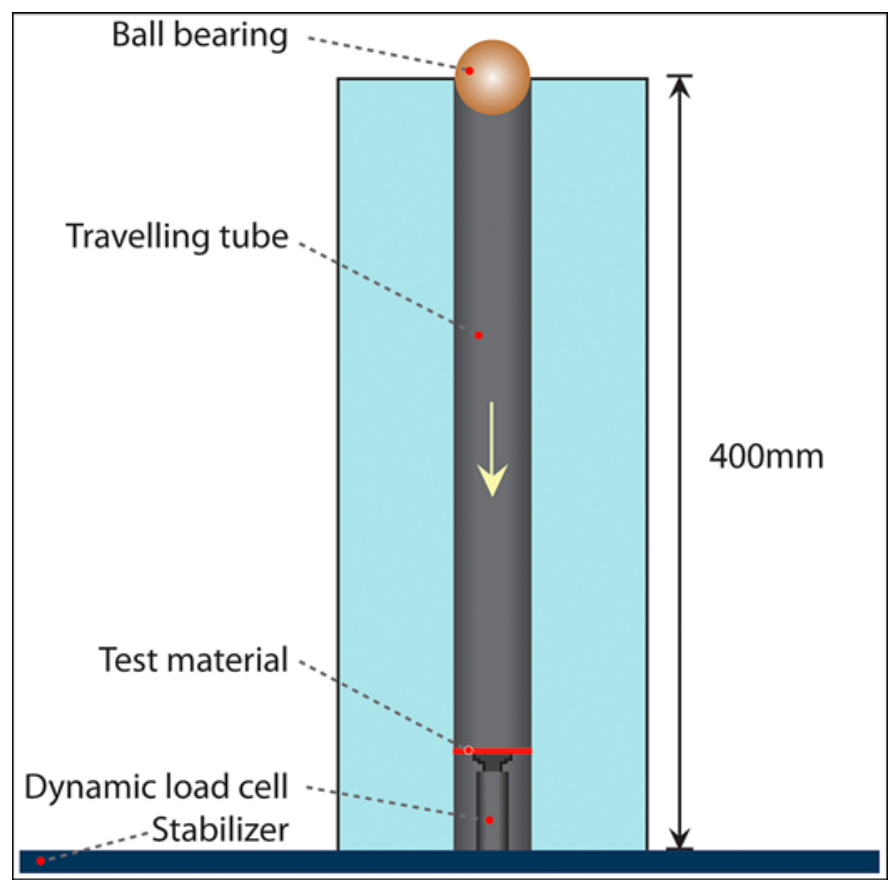

Figure 1.

Instrumentation for measuring force reduction performance of orthotic insole materials.

to conform the materials to the foot shape in order to homogenize the plantar pressure.

\section{Evaluation of Insole-Skin Friction Properties}

In this study, a new approach for measuring the dynamic coefficient of friction and shearing angle was adopted to simulate the contact condition between the 
plantar surface of the foot and the insole materials. The frictional property of the insole material was determined by using a friction measurement rig connected with an Instron machine sliding at a constant rate of extension. As shown in Figure 2, a dead weight was wrapped in pigskin as the contact surface of the foot skin. Pigskin has been used in a number of clinical research studies and recognized as having many similarities with human skin [20-25]. The pigskin was connected to the Instron tensile tester with a nylon filament. By measuring the peak force at which the whole assembly was continuously sliding, we determined the dynamic coefficients of friction of the insole materials. A vertical line was also marked on the bottom of the pigskin. Upon movement of the whole assembly during the determination of the coefficient of friction, the degree of the line slanting to the force direction was measured (Figure 3). The shear angle is defined as the degree of angle that changes at peak frictional force and at the commencement of the experiment.

Considering that it is generally suggested for patients to put on cotton socks for maximum protection as a practical measure, we developed a sock interface (98\% cotton, $2 \%$ Spandex) to cover the pigskin with a layer of fabric. The dynamic coefficient of friction between the sock interface and test materials and the shear angle were recorded.

\section{Evaluation of Thermal Comfort Properties}

The moisture regain and water vapor transmission rate of the insole materials were measured. A total of 12 types of materials with different thicknesses were evaluated. The moisture regain was measured under standard test method ASTM D1909 with a Mettler Toledo LJ16 moisture analyzer (Columbus, Ohio). The insole material chips were heated at $105^{\circ} \mathrm{C}$ for $3 \mathrm{~min}$ inside the moisture analyzer. The percentage of moisture regain was calculated with Equation (2):

$$
M_{\text {water }} / M_{\text {dry }} \times 100 \%,
$$

where $M_{\text {water }}$ is the mass of the absorbed water (g), and $M_{\text {dry }}$ is the dry mass of the sample (g).

The water vapor permeability of the insole materials was examined using standard test method ASTM E96. A single layer of each material with a diameter of $10 \mathrm{~cm}$, attached to a dish filled with distilled water, was weighed before and after the testing (Equation 3). The weight of the dish assembly decreased if water was transferred from one side to the other through the material.

$$
\text { Water Vapor Transmission rate }=\mathrm{G} /(t \times A) \text {, }
$$

where $G$ is the weight change (g), $t$ is the time during which $G$ occurs (h), and $A$ is the test area $\left(\mathrm{m}^{2}\right)$.

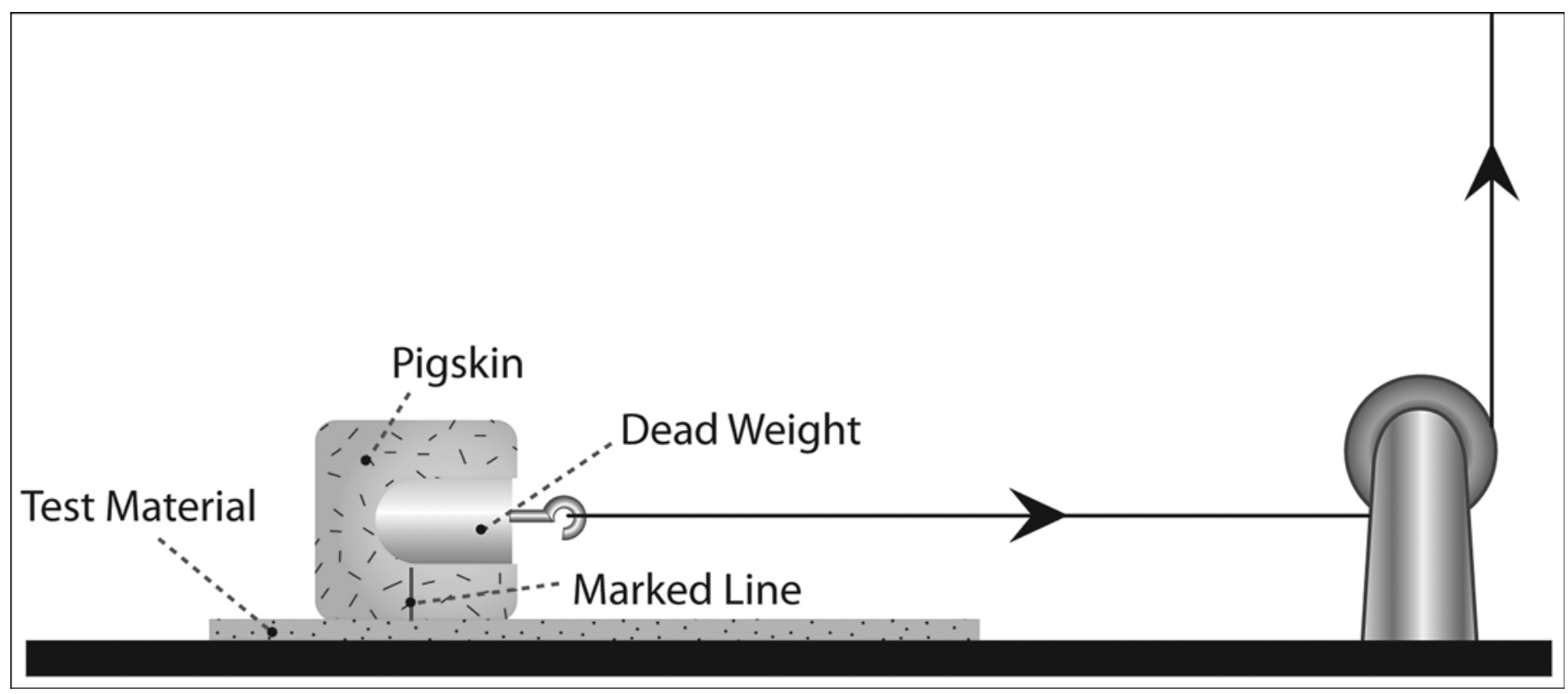

Figure 2.

Equipment setup for coefficient of friction and shearing angle measurement of insole materials at commencement of testing. 


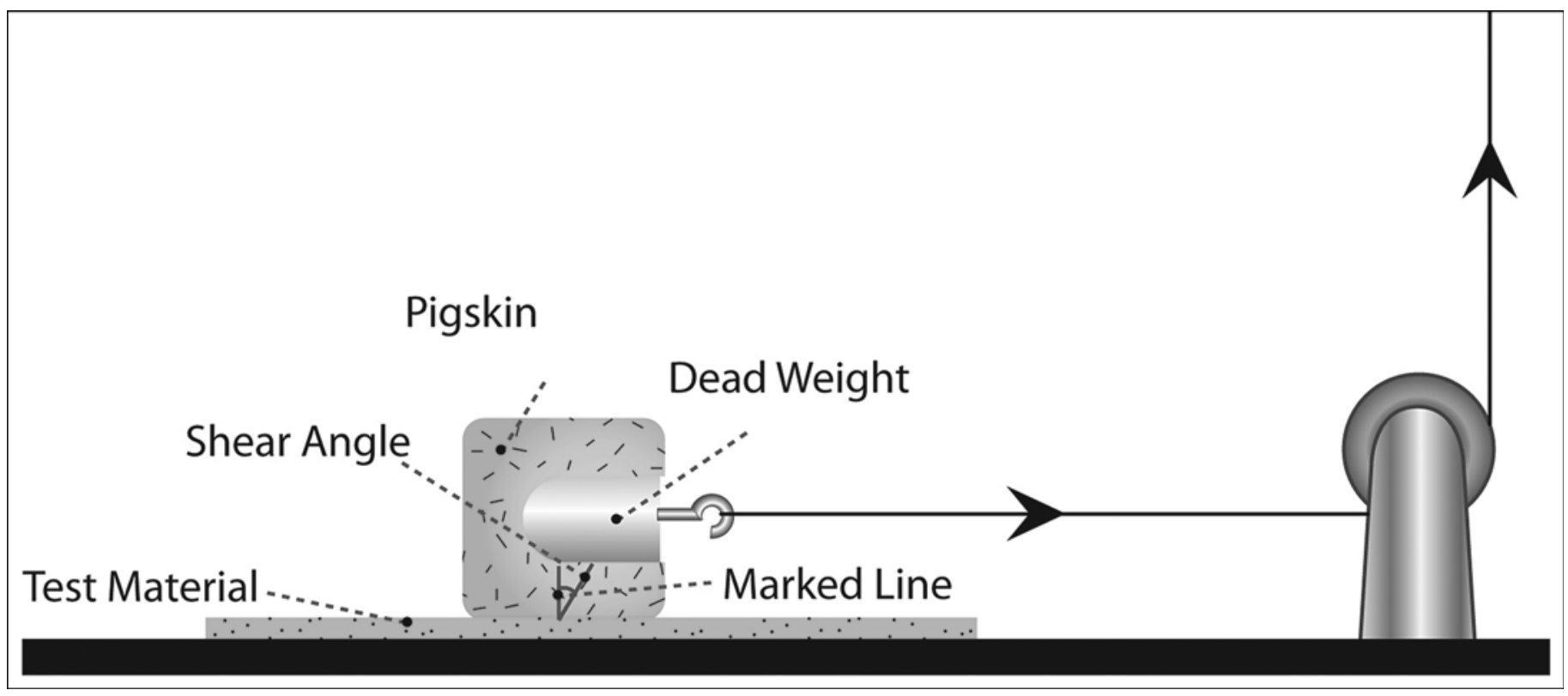

Figure 3.

Equipment setup for measuring coefficient of friction and shearing angle at peak frictional force.

\section{Performance Index}

To optimize the choice of insole fabrication and protection of the diabetic foot from ulcerations, we proposed a PI that combines various material test results together. Based on clinical practice of using a laminate of several materials with varying properties in foot orthoses, the key requirements of the insole fabrication for a plurality of layers were first defined in terms of (1) accommodation, (2) cushioning, and (3) control. Accommodation material that is in contact with the foot should be soft and conform to the foot shape, as well as be able to absorb and remove water vapor from perspiration in order to prevent any discomfort. Cushioning material located beneath the accommodative material should act as a shock absorber that can minimize shock transmissions to the foot, particularly at bony prominences. To optimize comfort, the cushioning material should also have moisture-absorbing properties and water vapor permeability. In the case of the bottom layer, a rigid, stiff, and high-density material should be used as the control material to provide support and stability to the assembly, allow for realignment of the foot, and even facilitate correction for requisite joint motion caused by severe foot deformities [12,20].

A PI matrix was then formulated in response to the key properties of the insole materials identified [14]. On the basis of the physical and thermal comfort property results, the PIs with respect to accommodation, cushioning, and control functions could be objectively quantified. As shown in Table 2, the materials tested for each property were divided into three groups of low, medium, and high to better fit clinical requirements by using mean and median statistic tools. Materials with results that ranged between the mean and median belong to the medium group. Materials with results greater than the mean and median belong to the high group. Otherwise, materials were allocated to the low group. Each property was given a score if the material met the requirements of

Table 2.

Performance index matrix.

\begin{tabular}{lcll}
\hline \multicolumn{1}{c}{ Measure } & Accommodation & Cushioning & Control \\
\hline Density & Low & Medium & High \\
Hardness & Low & Medium & High \\
Force Reduction & Low & High & High \\
Compression Stress & Low & Medium & High \\
Coefficient of Friction & Low & N/A & N/A \\
Shearing & Low & N/A & N/A \\
Moisture Regain & High & High & N/A \\
Water Vapor Permeability & High & High & N/A \\
Performance Index & Optimal & Optimal & Optimal \\
& Score & Score & Score \\
\hline N/A = not applicable. & & & \\
\hline
\end{tabular}


the low, medium, or high group. The PI for each material was calculated, which resulted in three scores that correspond to the ability of the material to perform the three categorized functions defined in the matrix. Some properties, which were not considered for a particular function, were marked as not applicable, which indicated that no score would be counted in the end. A higher score means greater suitability of the material for the task. A maximum score of 100 indicates high suitability for different purposes.

With the support of two hospital prosthetic and orthotic units in Hong Kong, we developed a rating factor for each key requirement of the orthotic insole materials for patients with diabetes. The performance indexes with respect to accommodation, cushioning, and control were calculated with the Equations (4)-(6):

$$
\begin{aligned}
\mathrm{PI}_{\text {accomodation }}= & D_{\text {low }}+H_{\text {low }}+\mathrm{FR}_{\text {low }}+\mathrm{SS}_{\text {low }}+\mathrm{COF}_{\text {low }}+ \\
& S_{\text {low }}+\mathrm{MR}_{\text {high }}+\mathrm{WVP}_{\text {high }}, \\
\mathrm{PI}_{\text {cushioning }}= & D_{\text {medium }}+H_{\text {medium }}+\mathrm{FR}_{\text {high }}+\mathrm{SS}_{\text {medium }}+ \\
& \mathrm{MR}_{\text {high }}+\mathrm{WVP}_{\text {high }}, \\
\mathrm{PI}_{\text {control }}= & D_{\text {high }}+H_{\text {high }}+\mathrm{FR}_{\text {high }}+\mathrm{SS}_{\text {high }},
\end{aligned}
$$

where PI is the performance index for the accommodation function, $D_{\text {low }}$ is the score for low density, $H_{\text {low }}$ is the score for low hardness, $\mathrm{FR}_{\text {low }}$ is the score for low force reduction, $\mathrm{SS}_{\text {low }}$ is the score for low stress/strain, $\mathrm{COF}_{\text {low }}$ is the score for low coefficient of friction, $\mathrm{S}_{\text {low }}$ is the score for low shearing, $\mathrm{MR}_{\text {high }}$ is the score for high moisture regain, and $\mathrm{WVP}_{\text {high }}$ is the score for high water vapor permeability.

\section{Statistical Analysis}

All data were summarized using SPSS statistical software (IBM; Armonk, New York). The reliability of each test was assessed by an intraclass correlation coefficient (ICC) to compare within-trial variability [26-30].

\section{RESULTS}

\section{Mechanical Properties of Insole Materials}

We used a dynamic load cell to record the peak forces of the insole materials and then calculate their force reduction percentages. As shown in Table 3, the force reduction percentages range from 38.9 to 82.5 percent among the seven samples studied (ICC $=0.998$ ). All samples had a noticeable force reduction when compared with the control ( $>400 \mathrm{~N}$ ). Sample D (Nora Lunalight A, Nora Systems Inc; Salem, New Hampshire) exhibited the highest force reduction percentage ( $>82 \%)$, while sample G (Pelite, TaiTak PVC Leather Co; Dongguan, China) had the lowest force reduction percentage of 38.9 percent.

The compression stress of the insole materials ranged from 98 to $1,139 \mathrm{kPa}$ (ICC $=0.990$ ). Sample D showed the highest resistance to compression forces $(>1,100 \mathrm{kPa})$, whereas sample E (Plastazote, NMC Cellfoam Oy; Laitila, Finland) showed the lowest stress of $98 \mathrm{kPa}$. Figure 4 depicts the relationship between the density, hardness, and compression stress behavior. The scatters are fairly linear. Both density and hardness show a positive slope, which

\begin{tabular}{|c|c|c|c|c|c|c|c|c|}
\hline \multirow[b]{2}{*}{ Sample } & \multirow{2}{*}{$\begin{array}{l}\text { Density } \\
\left(\mathrm{g} / \mathrm{cm}^{3}\right)\end{array}$} & \multirow{2}{*}{$\begin{array}{l}\text { Hardness } \\
\text { (Shore A) }\end{array}$} & \multirow{2}{*}{$\begin{array}{c}\text { Force } \\
\text { Reduction } \\
(\%)\end{array}$} & \multirow{2}{*}{$\begin{array}{c}\text { Compression } \\
\text { Stress (kPa) }\end{array}$} & \multicolumn{2}{|c|}{ Without Sock } & \multicolumn{2}{|c|}{ With Sock } \\
\hline & & & & & $\begin{array}{l}\text { Coefficient } \\
\text { of Friction }\end{array}$ & Shear $\left(^{\circ}\right)$ & $\begin{array}{l}\text { Coefficient } \\
\text { of Friction }\end{array}$ & Shear $\left(^{\circ}\right)$ \\
\hline B & 0.12 & 22 & 60.73 & 173 & 0.44 & 13.50 & 0.35 & 10.71 \\
\hline $\mathrm{C}$ & 0.23 & 25 & 41.18 & 233 & 0.47 & 14.15 & 0.36 & 11.76 \\
\hline $\mathrm{F}$ & 0.14 & 35 & 41.07 & 275 & 0.37 & 8.52 & 0.24 & 7.12 \\
\hline G & 0.08 & 20 & 38.91 & 104 & 0.42 & 12.07 & 0.31 & 10.28 \\
\hline
\end{tabular}
indicates a positive relationship with compression stress; a denser or harder insole material shows more resistance to

Table 3.

Summary of mechanical properties of insole materials. 


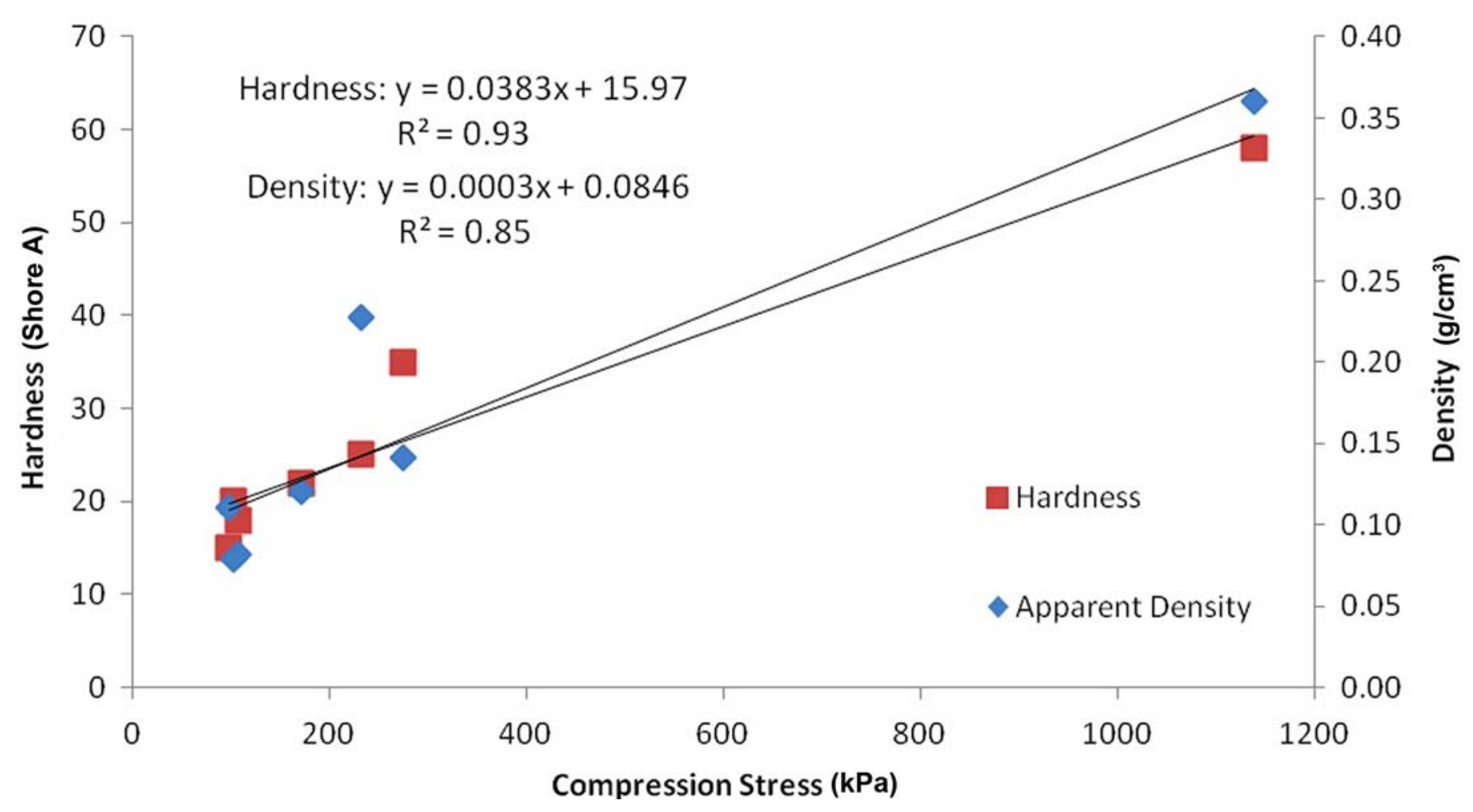

Figure 4.

Relationship between material hardness, density, and compression stress.

compression force. Their correlation coefficients $\left(R^{2}\right)$ are noticeably high (0.85 and 0.93 ), which indicate a high degree of linear relationship between the density-stress and hardness-stress behaviors.

As revealed in the force-time diagram in Figure 5, considerable differences in force absorption behavior and reacting time were observed among the insole materials. The curves obtained from samples B, D, and F were somewhat alike, each with a sharp peak force and short reacting time so that the high-impact forces imposed by the ball were effectively absorbed within a short period of time. They had good energy absorption and transformation performance. Samples A, C, E, and G, however, demonstrated a flat peak curve and relatively long reacting time. Their low peak force values and prolonged time intervals indicated a gradual force absorption and energy buffer against impact forces. Sample $G$ showed the longest reaction time interval with the lowest force reduction percentage among the seven types of tested materials.

\section{Insole-Skin Friction Properties}

The dynamic coefficients of friction and shear angles of the insole materials are presented in Table 3 . The coef- ficient of friction and shear angle between the pigskin and insole interface range from 0.32 to 0.54 and $3.8^{\circ}$ to $15.3^{\circ}$ (ICC $=0.871$ and 0.840 ), respectively. In the case of the sock interface, the coefficient of friction and shear angle range from 0.22 to 0.39 and $3.7^{\circ}$ to $12.4^{\circ}$ (ICC = 0.906 and 0.875$)$, respectively. The results indicate that the coefficient of friction and shear angles produced from the insole-sock interface are consistently smaller than that of the insole-skin interface. Among the samples, sample A exhibited the highest coefficient of friction (0.39) and shear angle $\left(12.4^{\circ}\right)$, while sample $E$ had the lowest values of 0.22 and 3.70. Samples A, B, C, and G had larger shear angles $\left(>10.2^{\circ}\right)$, while samples D, E, and $\mathrm{F}$ had considerably smaller shear angles $\left(<7.1^{\circ}\right)$. Materials with high shear angles also result in high coefficients of friction. The overall coefficients of friction, shear angles, and their relationships are presented in Figures 6 and 7. They have a positive strong linear relationship, which depicts a high value of the correlation coefficient $\left(R^{2}>0.95\right)$. The scatter is somewhat linear for both the insole-sock and insole-skin interfaces. 


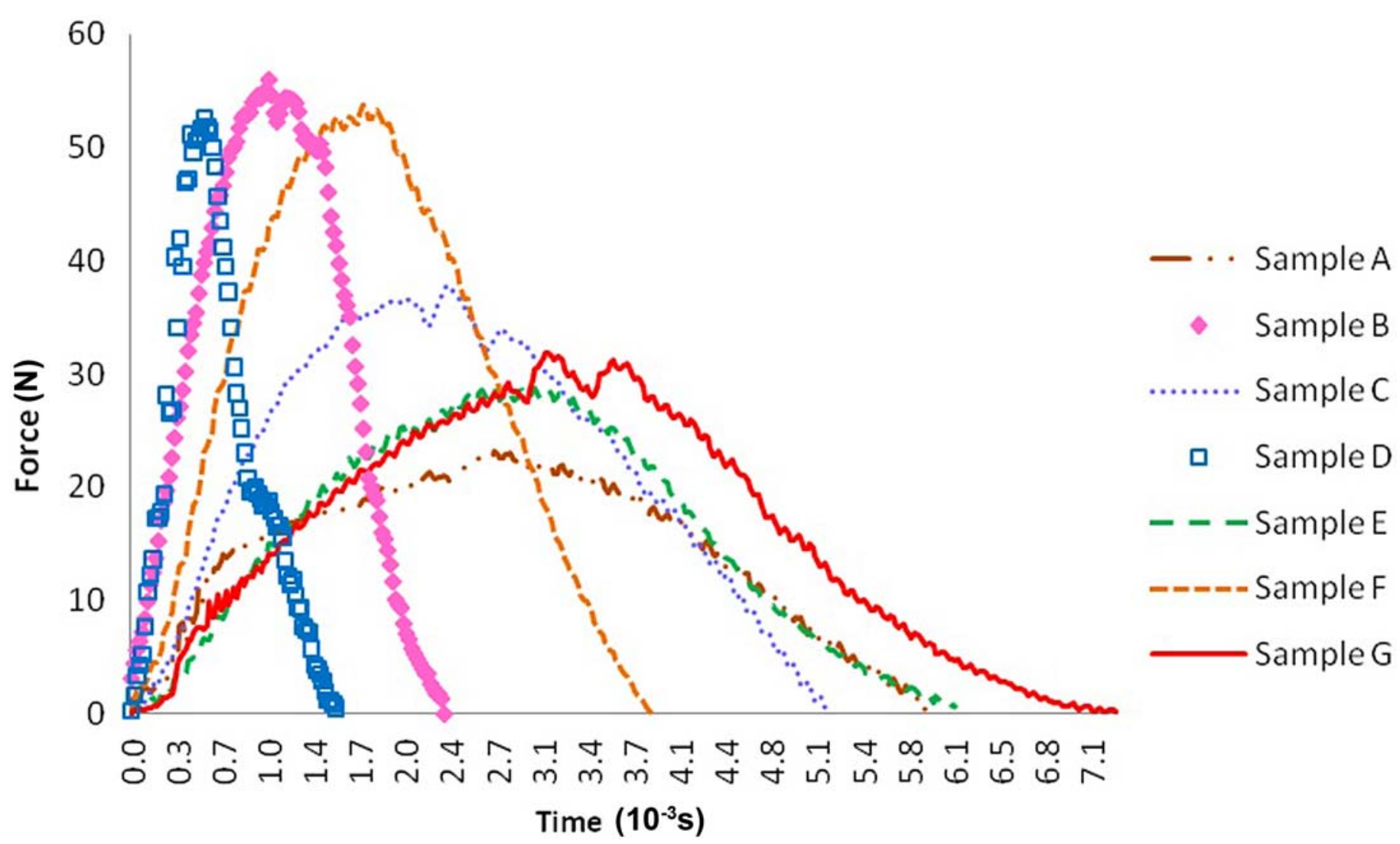

Figure 5.

Force-time graph for force absorption behavior of insole materials. Refer to Table 1 for material descriptions.

\section{Thermal Properties of Insole Materials}

The moisture regain percentages ranged from 1.01 to 3.69 percent (ICC $=0.90$ ) among the 12 samples studied. Samples A and E resulted in high percentages of moisture regain (>3.30\%). Sample F (High Density EVA, Tai Tak PVC Leather Co) had an outstanding lower moisture regain percentage of 1.01 percent; the material only absorbed a modest amount of the moisture inside. We observed that materials with a high percentage of moisture regain may be resultant of low density. Samples A, E, and $G$ with relatively lower densities of $0.08 \mathrm{~g} / \mathrm{cm}^{3}$, $0.11 \mathrm{~g} / \mathrm{cm}^{3}$, and $0.08 \mathrm{~g} / \mathrm{cm}^{3}$ demonstrated considerably higher moisture regain percentages of 3.36, 3.69, and 2.20 percent, respectively. In contrast, Sample D with a relatively higher density of $0.36 \mathrm{~g} / \mathrm{cm}^{3}$ displayed a fairly lower moisture regain percentage of 1.80 percent.

In terms of water vapor permeability, Figure 8 reveals that sample B(I) (Nora Lunairflex) (with a thickness of $3.1 \mathrm{~mm}$ ) has the highest water vapor permeability $\left(10.9 \mathrm{~g} / \mathrm{h} \cdot \mathrm{m}^{2}\right)$, showing that water vapor can readily pass through the material (ICC $=0.871$ ). The water vapor permeability obtained from sample B(II) (with a thickness of $6.1 \mathrm{~mm}$ ) was $5.4 \mathrm{~g} / \mathrm{h} \cdot \mathrm{m}^{2}$; its thickness was approximately twice that of sample $B(I)$, while its water vapor permeability is half that of sample $\mathrm{B}(\mathrm{I})$. A similar trend of reduction in water vapor permeability can be observed in samples $\mathrm{C}$ and $\mathrm{D}$. The thickness of the insole material indicates an adverse relationship with water vapor permeability; the water vapor permeability values are reduced with an increase in the material thickness. The moisture regain percentage and water vapor permeability values obtained from samples D(I), D(II), and D(III) are consistently lower than those of the remaining samples studied. This may be explained by their dense cell structure, meaning water vapor cannot be retained inside the cell or may fail to move freely in and out of the cell.

\section{Performance Index}

Table 4 summarizes the PIs of insole materials with respect to accommodation, cushioning, and control. The 


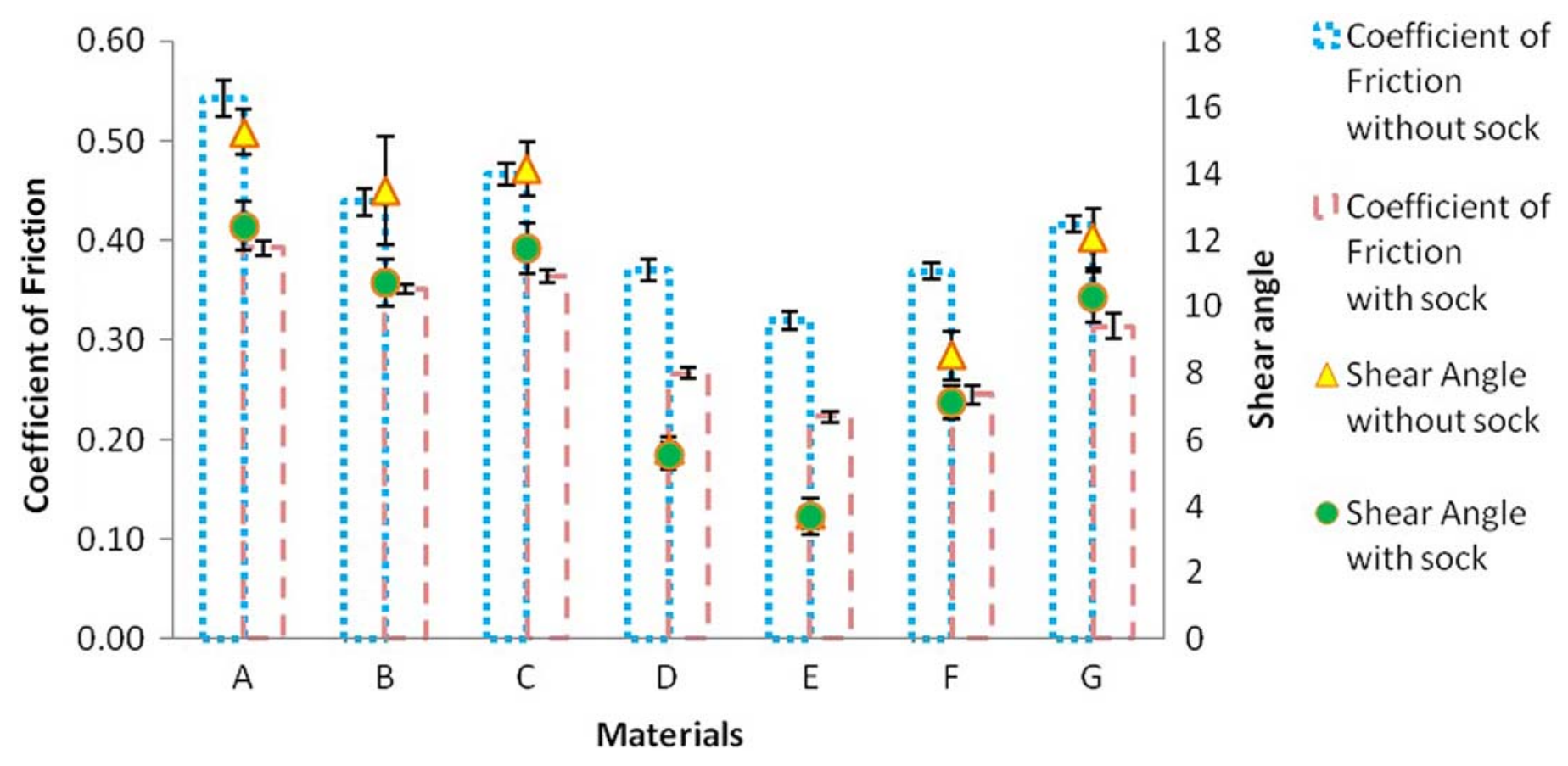

Figure 6.

Coefficients of friction and shear angles for insole-sock and insole-skin interfaces. Refer to Table 1 for material descriptions.

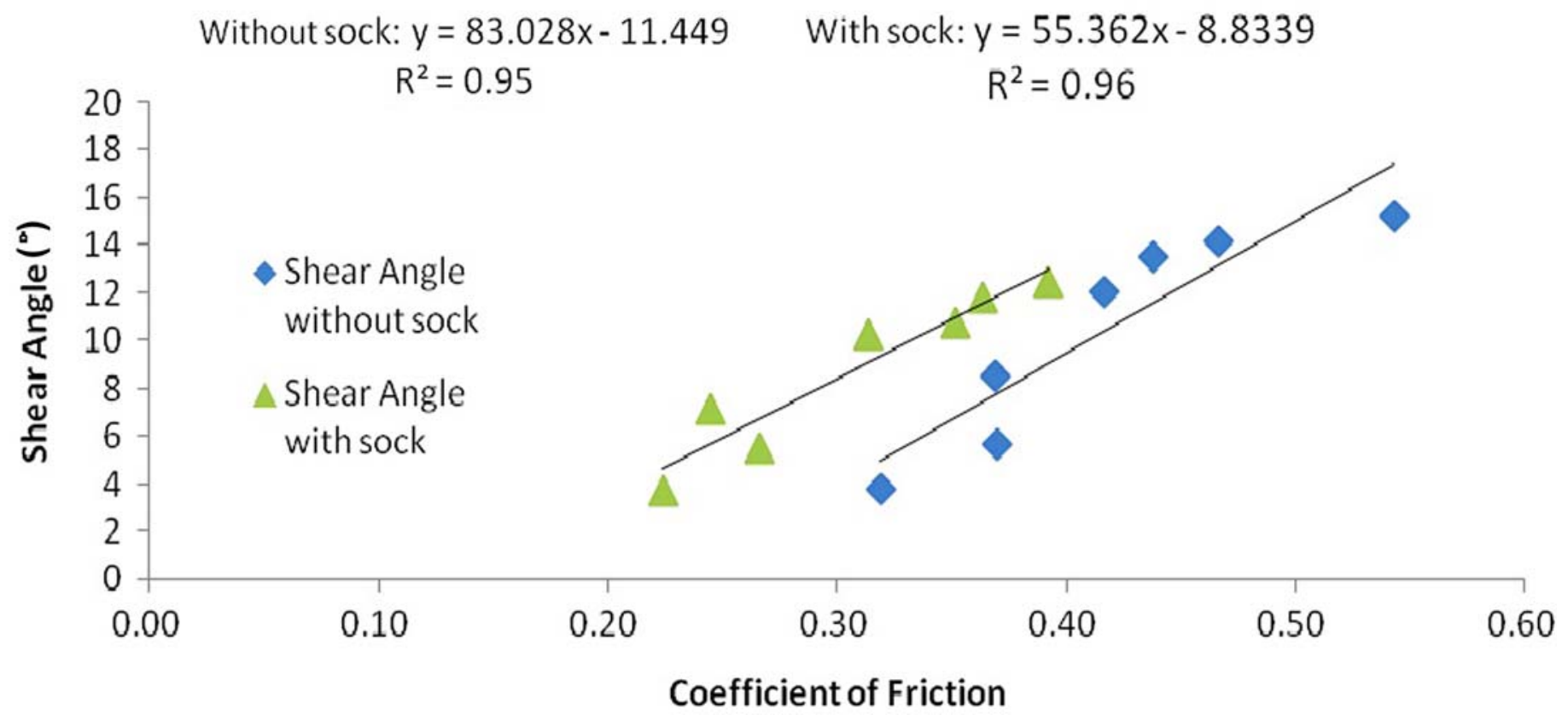

Figure 7.

Relationship between coefficients of friction and shear angles for insole-sock and insole-skin interfaces. 


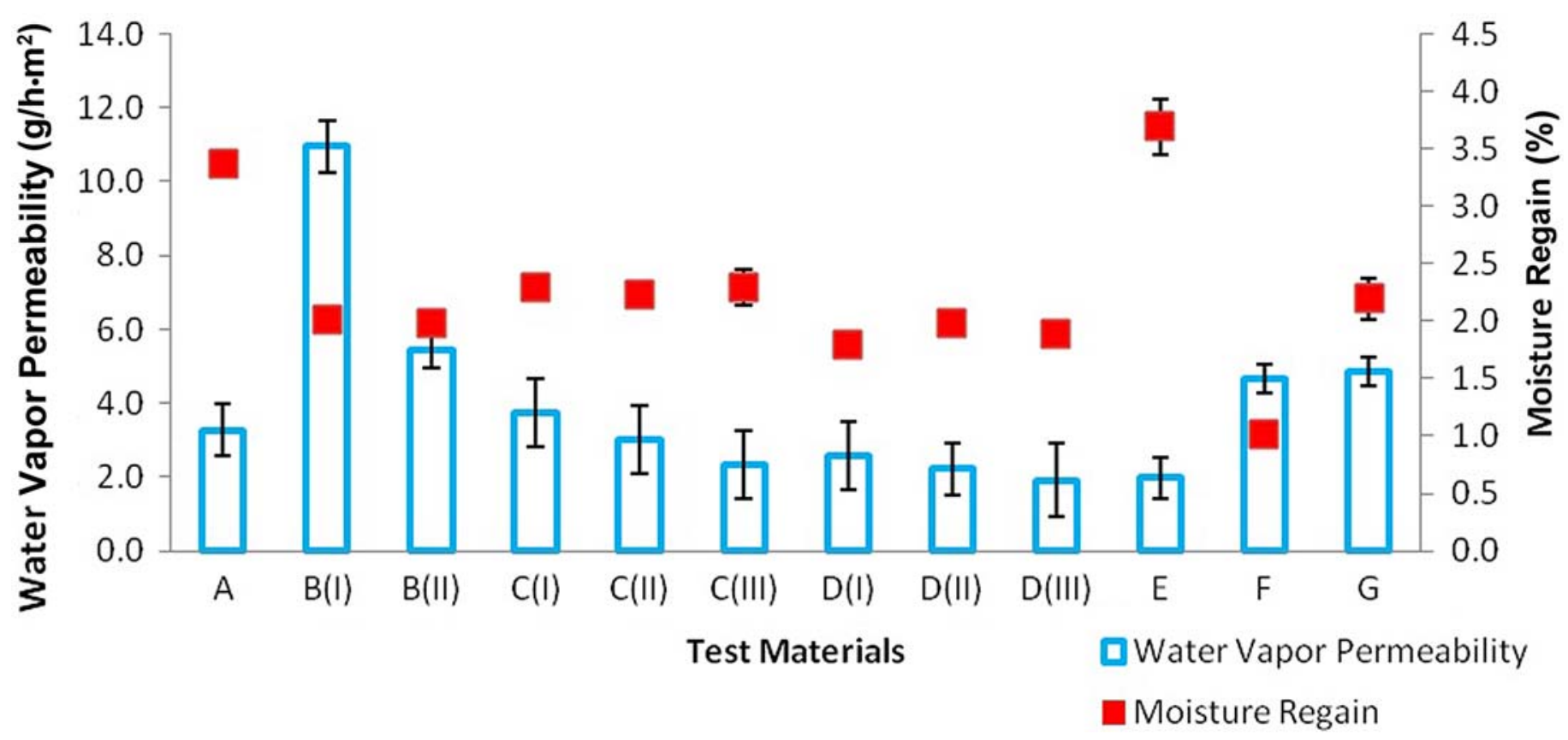

Figure 8.

Water vapor permeability and moisture regain percentage of test material. Refer to Table $\mathbf{1}$ for material descriptions.

PI for accommodation ranges from 30.6 to 67.2. Sample $\mathrm{E}$ was the most accommodating material because it has the highest score of 67.2, while sample D had the lowest score of 30.6. In terms of cushioning, sample C (Nora Lunalastike) had the highest score of 67.0 , while sample $\mathrm{G}$ had the lowest score of 3.45. In the case of control, sample D had a full maximum score of 100 . In contrast, samples $\mathrm{C}$, E, and $\mathrm{G}$ had a score of 0 , so they are not suitable for use as a control layer.

\section{DISCUSSION}

In this study, all tested materials displayed force reduction either with a sharp peak force that had a short reacting time or a flat peak curve with a long reacting time. Sample D had the best performance in attenuating the impact force, while the rest of the materials demonstrated less force reduction ability. Nonetheless, the force and time graph reveal that these materials may be able to attenuate force by means of prolonging the time for the impact. It can be seen from the force-time graph in Figure 5 that there is a time requirement for the impulse displayed for the impact of a particular material. The materials with prolonged time requirement for impulse
Table 4.

Performance index results.

\begin{tabular}{lccc}
\hline Materials & Accommodation & Cushioning & Control \\
\hline $\mathrm{A}$ & 36.61 & 34.49 & 19.23 \\
$\mathrm{~B}$ & 38.89 & 31.04 & 19.23 \\
$\mathrm{C}$ & 31.05 & $\mathbf{6 8 . 9 7}$ & 0.00 \\
$\mathrm{D}$ & 30.56 & 27.59 & $\mathbf{1 0 0}$ \\
$\mathrm{E}$ & $\mathbf{6 7 . 1 7}$ & 6.90 & 0.00 \\
$\mathrm{~F}$ & 63.89 & 48.28 & 30.77 \\
$\mathrm{G}$ & 50.00 & 3.45 & 0.00 \\
Note: Highest score in each column highlighted. Refer to Table 1 for material \\
descriptions.
\end{tabular}

show a better performance in offsetting the load and buffering. Therefore, the force applied onto the material will be gradually lost. The force reduction property of the insole material is therefore important to protect the foot from unexpected shocks and/or gait termination.

The results indicate that the magnitude of the shearing load imposed on the pigskin is highly correlated with the coefficient of friction of the material. Materials with high frictional force on the skin resulted in a high shearing load. The dynamic coefficients of friction and the shear angles of the insole-sock interface are consistently lower than those of the insole-skin interface. This is why most 
foot-care providers suggest patients with diabetes wear socks, because the socks can reduce the shear and rubbing within plantar tissues, thereby reducing the potential for the formation of various foot lesions [30]. The results are also highly consistent with the discussions in previous studies, in which an increase in the coefficient of friction will result in increasing the shear force [14]. Nevertheless, further research is needed to investigate the effects of the fabric contents, knitting structures, and design of the socks on shear and friction forces on the plantar tissues to avoid callus formation, excessive heat from friction, and repetitive microtrauma beneath the foot.

In terms of the thermal comfort properties, it is possible to attain a broad understanding of the performance of the materials used with respect to moisture content and water vapor permeability for the orthotic purposes of diabetic patients because the comfort of the feet is highly related to the skin temperature and humidity of the microclimate inside the orthotic insoles [31]. The moisture regain percentage shows the ability to absorb moisture from the air at a standard temperature and relative humidity. We observed considerable differences in thermal comfort properties among the samples of different brands. Samples with lower densities may result in higher percentages of moisture regain, while denser samples may have lower moisture content. Less dense materials, such as samples A (Nora Lunairmed) and E (Plastazote), have high moisture absorption because there are more spaces and gaps among the foam cells, thus allowing considerable amounts of water to be retained inside their structures. Apart from foam density, cell volume tends to be a key factor that affects the performance of moisture absorption. Sample C (Nora Lunalastike), which is a comparatively dense material among the materials studied, does not absorb moisture to a great extent because of its larger cell volume. In contrast, sample D (Nora Lunalight A) exhibited noticeably low moisture regain because of its higher density together with smaller cell size. As a result, materials with low density structures and large foam cell size are suitable for use in direct contact with the feet because they can absorb a greater amount of moisture that has accumulated inside the orthotic insoles. The material is not only able to absorb moisture for better comfort but also enhances resistance to static build up.

In addition, water vapor permeability demonstrates the ability for heat dissipation and moisture transfer. A material with good water vapor permeability enables faster heat dissipation and reduces the foot temperature. It is also an indicator of breathability, which can enhance the overall comfort inside the orthotic insoles [32]. Sample B (Nora Lunairflex) is most permeable to water vapor because of its perforated structure, which allows the free movement of water vapor. Since material thickness shows an adverse relationship with water vapor permeability because thicker materials may contain more cells that restrain water vapor transfer, thin insole materials are highly recommended as a covering material in insole fabrication to enhance water vapor transmission within the in-shoe environment.

Although the use of orthotic insoles is well accepted in clinical practice, limited information is available for the selection of fabrication materials for orthotic insoles. Standards for the classification of materials are also not well established. With regards to the practical use of orthotic insoles for patients with diabetes, this study has demonstrated the use of PIs that combine various key requirements and material test results together and provide practical guidelines on the choice of insole fabrication so as to optimize the protection of the diabetic foot from ulcerations. For example, the Nora Lunalight A samples show excellent performance, reducing impact forces up to 80 percent during gait and withstanding compression forces above $1,100 \mathrm{kPa}$ before deformation. Insoles made of Nora Lunalight A may produce less frictional force and shearing stress to the skin, which may prevent callus formation and tissue damage. Nevertheless, in considering the major effects of moisture regain and water vapor permeability for accommodation purposes, Nora Lunalight A is not recommended for use as a covering material to provide an interface with the skin of the foot because of its poor thermal comfort performance. On the contrary, Plastazote is the most accommodating material. It has the lowest friction surface, which reduces the shearing stress induced onto the foot skin and the lowest compression stress, which shows a high ability to conform to foot shape. Insoles made of Plastazote will have an outstanding moisture regain percentage (3.7\%), in which any moisture produced inside the foot climate can be easily absorbed so as to improve the comfort and breathability of the insole. Nonetheless, Plastazote is not suggested for cushioning and control purposes because it may not be able to absorb the impact energy during gait or resist compression stress $(<98 \mathrm{kPa})$, so it may deform easily.

In view of the PI, Nora Lunalastike exhibits moderate hardness (Shore 25) and compression stress resistance 
(>230 kPa) to provide acceptable durability with a certain amount of conformation to relief plantar pressure. Insole fabrication that uses Nora Lunalastike materials could also absorb moisture produced from the foot so as to maintain the comfort of patients with diabetes. With respect to the requirement for a high stress resistance and hardness for control purposes or low frictional force and shearing stress for accommodation purposes, Nora Lunalastike is likely the most suitable for a cushioning material. Nora Lunairflex has outstanding performance in absorbing energy, with a level above 60 percent during impact, and ability to transfer water vapor through the material that is above $5 \mathrm{~g} / \mathrm{h} \cdot \mathrm{m}^{2}$. It can also conform well to the foot shape. Nonetheless, insoles made of Nora Lunairflex will produce a higher frictional force and shearing stress that may not meet the requirements of a covering material. On the other hand, it is fairly soft and will significantly deform, which may not be suitable for use for either cushioning or control purposes. The PI suggests that Nora Lunairflex may not contain the desired characteristics or any type of application in this study even though it has scored somewhat higher for being accommodating at 38.89 compared with the other types of applications.

\section{CONCLUSIONS}

With advances in material sciences in recent years, a wide range of foam materials for insole fabrication has been introduced into the market. Nevertheless, traditional test methods cannot be solely used as the indicator for assessing the suitability of an orthotic material in response to the practical use of orthotic insoles. The new approach of shear property evaluation might be able to objectively examine the magnitude of the shearing stress induced from the insole materials. The shearing stress results of insole materials appear to be clearly correlated with the coefficients of friction. The thermal comfort data provide clinical significance for determining the performance of moisture absorption and water vapor permeability of materials used for orthotic purposes for diabetic patients, in which the importance was often neglected in previous articles. The experimental conditions may not be able to fully replicate the in-shoe microclimate environment; however, this study provides some preliminary data on evaluating the thermal comfort properties of insole materials. The studies need to be extended to design in-shoe simulation testing conditions for more accurate and real case investigation.

Based on this study, the physical and thermal comfort properties are strategically combined and quantified in the form of the PI according to the primary role of orthotic insoles. The indexes demonstrate consistency with the clinical practices of the prosthetic and orthotic units in local hospitals in that the corresponding Nora insole materials have been deliberately selected in the treatment of diabetes. The PIs therefore provide useful information for practitioners to gain a better understanding of the insole material properties in order to prescribe optimal custom-fabricated orthotic insoles for patients with diabetic foot.

\section{ACKNOWLEDGMENTS}

\section{Author Contributions:}

Study concept and design: W. T. Lo, K. L. Yick.

Acquisition of data: W. T. Lo.

Analysis and interpretation of data: W. T. Lo, K. L. Yick.

Drafting of manuscript: W. T. Lo.

Critical revision of manuscript for important intellectual content:

K. L. Yick, S. P. Ng, J. Yip.

Obtained funding: K. L. Yick.

Study supervision: K. L. Yick, S. P. Ng, J. Yip.

Financial Disclosures: The authors have declared that no competing interests exist.

Funding/Support: This material was based on work supported by the Department of Prosthetics and Orthotics at the Kowloon and Queen Elizabeth Hospitals in Hong Kong, as well as funded by the Research Grant Council (PolyU 5308/11E).

\section{REFERENCES}

1. Cavanagh PR, Ulbrecht JS. The biomechanics of the foot in diabetes mellitus. In: Levin ME, O’Neal LW, editors. The diabetic foot. 7th ed. Philadelphia (PA): Mosby; 2008. p. 115-84.

2. Reiber GE, Vileikyte L, Boyko EJ, del Aguila M, Smith DG, Lavery LA, Boulton AJ. Causal pathways for incident lower-extremity ulcers in patients with diabetes from two settings. Diabetes Care. 1999;22(1):157-62. [PMID:10333919] http://dx.doi.org/10.2337/diacare.22.1.157

3. Tsung BY, Zhang M, Mak AF, Wong MW. Effectiveness of insoles on plantar pressure redistribution. J Rehabil Res Dev. 2004;41(6A):767-74. [PMID:15685465] http://dx.doi.org/10.1682/JRRD.2003.09.0139

4. Foto JG. Compact and portable digitally controlled device for testing footwear materials: Technical note. J Rehabil 
Res Dev. 2008;45(6):893-900. [PMID:19009475]

http://dx.doi.org/10.1682/JRRD.2007.07.0111

5. Carlson JM. Functional limitations from pain caused by repetitive loading on the skin: A review and discussion for practitioners, with new data for limiting friction loads. J Prosthet Orthot. 2006;18(4):93-103. http://dx.doi.org/10.1097/00008526-200610000-00002

6. Riordan J, Voegeli D. Prevention and treatment of pressure ulcers. Br J Nurs. 2009;18(20):S20-27, S22, S24-27. [PMID:20081668]

7. Crabtree P, Dhokia V, Ansell M, Newman S. Design and manufacturing of customised orthotics for sporting applications (P62). Engineering of Sport. 2008;7:309-17.

8. Fang MA, Taylor CE, Nouvong A, Masih S, Kao KC, Perell KL. Effects of footwear on medial compartment knee osteoarthritis. J Rehabil Res Dev. 2006;43(4):427-34. [PMID:17123182] http://dx.doi.org/10.1682/JRRD.2005.10.0161

9. van Netten JJ, Jannink MJ, Hijmans JM, Geertzen JH, Postema K. Use and usability of custom-made orthopedic shoes. J Rehabil Res Dev. 2010;47(1):73-81. [PMID:20437329] http://dx.doi.org/10.1682/JRRD.2009.08.0142

10. Reiber GE, Smith DG, Wallace CM, Vath CA, Sullivan K, Hayes S, Yu O, Martin D, Maciejewski M. Footwear used by individuals with diabetes and a history of foot ulcer. J Rehabil Res Dev. 2002;39(5):615-22. [PMID:17642026]

11. Foto JG, Birke JA. Evaluation of multidensity orthotic materials used in footwear for patients with diabetes. Foot Ankle Int. 1998;19(12):836-41. [PMID:9872471] http://dx.doi.org/10.1177/107110079801901208

12. Faulí AC, Andrés CL, Rosas NP, Fernández MJ, Parreño EM, Barceló CO. Physical evaluation of insole materials used to treat the diabetic foot. J Am Podiatr Med Assoc. 2008;98(3):229-38. [PMID:18487597]

13. Brodsky JW, Pollo FE, Cheleuitte D, Baum BS. Physical properties, durability, and energy-dissipation function of dualdensity orthotic materials used in insoles for diabetic patients. Foot Ankle Int. 2007;28(8):880-89. [PMID:17697652] http://dx.doi.org/10.3113/FAI.2007.0880

14. Paton J, Jones RB, Stenhouse E, Bruce G. The physical characteristics of materials used in the manufacture of orthoses for patients with diabetes. Foot Ankle Int. 2007; 28(10):1057-63. [PMID:17923055] http://dx.doi.org/10.3113/FAI.2007.1057

15. Lord M, Hosein R. A study of in-shoe plantar shear in patients with diabetic neuropathy. Clin Biomech (Bristol, Avon). 2000;15(4):278-83. [PMID:10675669] http://dx.doi.org/10.1016/S0268-0033(99)00076-5

16. Yavuz M, Erdemir A, Botek G, Hirschman GB, Bardsley L, Davis BL. Peak plantar pressure and shear locations: Relevance to diabetic patients. Diabetes Care. 2007;30(10):
2643-45. [PMID:17620447]

http://dx.doi.org/10.2337/dc07-0862

17. Hosein R, Lord M. A study of in-shoe plantar shear in normals. Clin Biomech (Bristol, Avon). 2000;15(1):46-53. [PMID:10590344] http://dx.doi.org/10.1016/S0268-0033(98)00059-X

18. Chen KY. Analysis: Designing footwear for patients with the diabetic foot. Diabetes Technol Ther. 2005;7(4):647-50. [PMID:16120041] http://dx.doi.org/10.1089/dia.2005.7.647

19. Mills K, Blanch P, Vicenzino B. Influence of contouring and hardness of foot orthoses on ratings of perceived comfort. Med Sci Sports Exerc. 2011;43(8):1507-12. [PMID:21233775]

20. Robertson G. Measurement of human skin compression dynamically using an automated photogrammetric technique. Proceedings of the ISPRS Congress Commission V; 2004 Jul 12-23; Istanbul, Turkey. p. 286-90.

21. Dick IP, Scott RC. Pig ear skin as an in-vitro model for human skin permeability. J Pharm Pharmacol. 1992;44(8): 640-45. [PMID:1359086] http://dx.doi.org/10.1111/j.2042-7158.1992.tb05485.x

22. Lim J, Hong J, Chen WW, Weerasooriya T. Mechanical response of pig skin under dynamic tensile loading. Int $\mathrm{J}$ Impact Eng. 2011;38(2-3):130-35.

http://dx.doi.org/10.1016/j.ijimpeng.2010.09.003

23. Herkenne C, Naik A, Kalia YN, Hadgraft J, Guy RH. Pig ear skin ex vivo as a model for in vivo dermatopharmacokinetic studies in man. Pharm Res. 2006;23(8):1850-56.

[PMID:16841197] http://dx.doi.org/10.1007/s11095-006-9011-8

24. Boudry I, Blanck O, Cruz C, Blanck M, Vallet V, Bazire A, Capt A, Josse D, Lallement G. Percutaneous penetration and absorption of parathion using human and pig skin models in vitro and human skin grafted onto nude mouse skin model in vivo. J Appl Toxicol. 2008;28(5):645-57.

[PMID:18041757] http://dx.doi.org/10.1002/jat.1317

25. Shergold OA, Fleck NA, Radford D. The uniaxial stress versus strain response of pig skin and silicone rubber at low and high strain rates. Int J Impact Eng. 2006;32:1384-1402. http://dx.doi.org/10.1016/j.ijimpeng.2004.11.010

26. De Mits S, Coorevits P, De Clercq D, Elewaut DD, Woodburn J, Roosen P. Reliability and validity of the INFOOT three-dimensional foot digitizer for patients with rheumatoid arthritis. J Am Podiatr Med Assoc. 2011;101(3):198-207. [PMID:21622631]

27. Schmid S, Hilfiker R, Radlinger L. Reliability and validity of trunk accelerometry-derived performance measurements in a standardized heel-rise test in elderly subjects. J Rehabil Res Dev. 2011;48(9):1137-44. [PMID:22234718] http://dx.doi.org/10.1682/JRRD.2011.01.0003 
JRRD, Volume 51, Number 2, 2014

28. Moloney NA, Hall TM, Doody CM. Reliability of thermal quantitative sensory testing: A systematic review. J Rehabil Res Dev. 2012;49(2):191-207. [PMID:22773522] http://dx.doi.org/10.1682/JRRD.2011.03.0044

29. Ghotbi N, Nakhostin Ansari N, Naghdi S, Hasson S. Measurement of lower-limb muscle spasticity: Intrarater reliability of Modified Modified Ashworth Scale. J Rehabil Res Dev. 2011; 48(1):83-88. [PMID:21328165] http://dx.doi.org/10.1682/JRRD.2010.02.0020

30. Li Y, Dai XQ, Zhang M, Cheung JT, Zhang X. Biomechanical engineering of textiles and clothing. Cambridge (England): Woodhead Publishing; 2006.

31. Martínez N, Rosa D, Gámez J, González JC, Chirivella C, Gutiérrez JM, Prat J, Sánchez JJ. A study of the influence of the environmental condition and the garment in skin temperature in sport activity (P119). Engineering of Sport. 2008;7: 631-39.

32. Jeong WY, Park JW, Kamijo M, Shimizu Y, An SK. Characteristics of artificial leather for footwear- heat and moisture transport properties. Sen-I Gakkaishi. 2007;63:271-75. http://dx.doi.org/10.2115/fiber.63.271

Submitted for publication January 16, 2013. Accepted in revised form August 16, 2013.

This article and any supplementary material should be cited as follows:

Lo WT, Yick KL, Ng SP, Yip J. New methods for evaluating physical and thermal comfort properties of orthotic materials used in insoles for patients with diabetes. J Rehabil Res Dev. 2014;51(2):311-24.

http://dx.doi.org/10.1682/JRRD.2013.01.0012

ResearcherID/ORCID: Wai Ting Lo: D-4078-2014

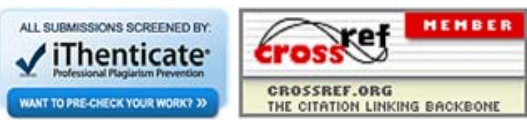

